\title{
Removal of ammonia and hydrogen sulfide from livestock farm by copper modified activated carbon
}

\author{
Zhang F., Liang M.*, Ye C. and Zhang C. \\ College of Environmental Science and Engineering, Taiyuan University of Technology, Jinzhong 030600, China \\ Received: 30/01/2020, Accepted: 18/05/2020, Available online: 19/05/2020 \\ *to whom all correspondence should be addressed: e-mail: liangmeisheng123@yeah.net \\ https://doi.org/10.30955/gnj.003282
}

\section{Graphical abstract}

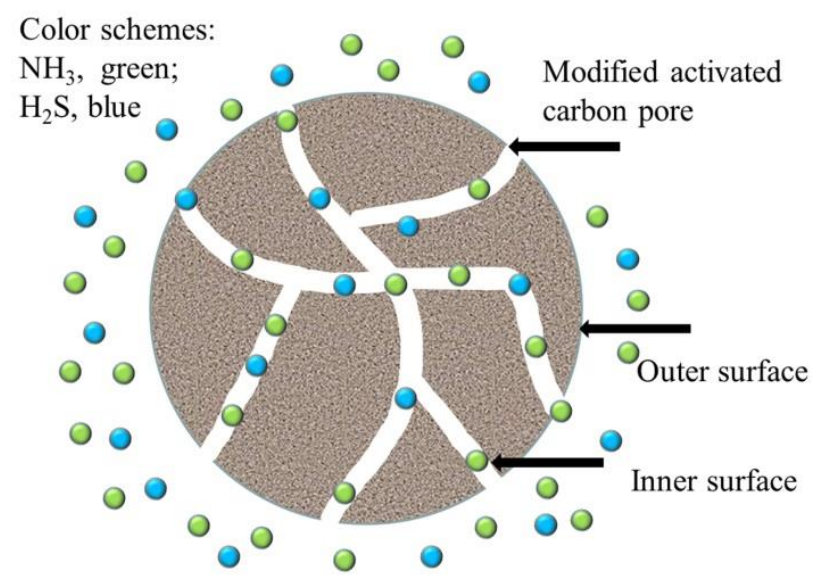

\section{Abstract}

Ammonia $\left(\mathrm{NH}_{3}\right)$ and hydrogen sulfide $\left(\mathrm{H}_{2} \mathrm{~S}\right)$, as the main odorous substances in waste gas from livestock farm, have attracted more attentions rescently since their adverse effects. To remove $\mathrm{NH}_{3}$ and $\mathrm{H}_{2} \mathrm{~S}$ efficiently, high-pressure hydrothermal modification (HPHM), metal salt solution impregnation modification (MSIM), and HPHM combined with MSIM are used to modify the activated carbon (AC). Meanwhile, the pore structure and surface functional groups of $A C$ and MAC absorbents are characterized by BET, FTIR and Boehm titration method. The adsorption performance of activated carbon (AC) and modified activated carbon (MAC) are compared. The effects of modification and operation conditions on the adsorption performance of $\mathrm{MAC}$ for $\mathrm{NH}_{3}$ and $\mathrm{H}_{2} \mathrm{~S}$ are studied in detail. It was found that the optimal adsorption performance of MAC can be achieved by high-pressure hydrothermal modification (HPHM) followed by the metal salt solution impregnation modification (MSIM). With gas space velocity of $900 \mathrm{~h}^{-1}$ and total inlet concentration of $550-650 \mathrm{mg} \mathrm{m}^{-3}$ at $50{ }^{\circ} \mathrm{C}$, the adsorption capacities of $\mathrm{NH}_{3}$ and $\mathrm{H}_{2} \mathrm{~S}$ of GS270CuCl6010 are $24.17 \mathrm{mg} \mathrm{g}^{-1}$ and $26.20 \mathrm{mg} \mathrm{g}^{-1}$, respectively. The adsorption of $\mathrm{NH}_{3}$ and $\mathrm{H}_{2} \mathrm{~S}$ by MAC is the result of both physical adsorption and chemical adsorption.
Keywords: Copper chloride, modified activated carbon, adsorption, $\mathrm{NH}_{3}$ and $\mathrm{H}_{2} \mathrm{~S}$.

\section{Introduction}

With the development of intensive livestock production in our country in recent years, the effluent pollution has attracted more increasing attentions (Li et al., 2016; Chen et al., 2014). Emission of different pollutant gases from livestock and poultry breeding, including methane $\left(\mathrm{CH}_{4}\right)$, nitric oxide(NOx), hydrogen sulfide $\left(\mathrm{H}_{2} \mathrm{~S}\right)$, ammonia $\left(\mathrm{NH}_{3}\right)$, carbon monoxide (CO), carbon dioxide $\left(\mathrm{CO}_{2}\right)$ and so on (Matulaitis, 2015); can cause one or more of the following adverse effects: threats to human health (Schiffman et al., 2016; Nicell, 2009); Injury to livestock (Osorio et al., 2009); deterioration of equipment in the livestock farm (Kim et al., 2008); serious complaints from neighbors (Kim et al., 2008); and the damage to ecosystems due to soil acidification and photochemical smog (Heber et al., 2006; Petit et al., 2007). $\mathrm{NH}_{3}$ and $\mathrm{H}_{2} \mathrm{~S}$, as the main odorous substances in waste gas from livestock farm, have attracted more attentions (Kim et al., 2008; Liao and Chen, 2008). The State Environmental Protection Administration of China approved and implemented Emission Standards for Odor Pollutants (GB14554-93), which sets relevant regulations for the emissions of $\mathrm{NH}_{3}$ and $\mathrm{H}_{2} \mathrm{~S}$ (Zheng et al., 2014).

Odor gas has features of dispersive emission source, low concentration of gases, large areas of production, and complex composition (Gao et al., 2004). Since 1960s, many researches have been reported on the odor gas of livestock and poultry in the world (Liu et al., 2017). The traditional treatment of odor gas, through physical, chemical, and biological means, has gradually developed from simple washing elimination to biological degradation and activated carbon adsorption removal. The removal rate of chemical cleaning is high, but the installation and operation cost increases because of the need of grade absorption treatment by several kinds of chemicals for the composition of pollutants in actual operation (Xu, 2007). Water washing elimination is not a very economical option because of amount of water requirements (Rene et al., 2012). Biological removal is easy to block the bed 
during the biofilm development because the moisture and $\mathrm{pH}$ value are difficult to control (Datta and Allen, 2005; Mudliar et al., 2010; Arellano-García et al., 2015).

In contrast, owing to advantages of simple process, high purification efficiency, good regeneration property and low price (Guo et al., 2005; Liu et al., 2005), adsorption removal by Activated carbon (AC) has been widely used in the treatment of odor gas from livestock farm. Activated carbon can be usually used as adsorbent, catalyst or catalyst carrier because of the large specific area, developed pore structure and unique surface chemical properties. The adsorption removal rate of $\mathrm{NH}_{3}$ and $\mathrm{H}_{2} \mathrm{~S}$ on activated carbon by simple raw activated carbon adsorption is limited and the adsorption capacity of $\mathrm{NH}_{3}$ is weaker than that of $\mathrm{H}_{2} \mathrm{~S}$ (Harihastuti et al., 2015). The size of $\mathrm{NH}_{3}$ molecules with a width of about $3 \AA$ is small, and $\mathrm{NH}_{3}$ molecules can be strongly adsorbed only in pores similar in size to its diameter at ambient conditions rather than in the majority of an average activated carbon pore in the range of $10-20 \AA$, resulting in the use of only the small fraction of adsorbent surface (Petit et al., 2007). Modifications by some physical or chemical methods on surface physical structure and chemical properties of activated carbon seemed to be effective for improving the adsorption performance of activated carbon (Petit et al., 2007; Liu et al., 2005; Guo et al., 2007). Acid or alkali modifications are widely used. AC modified by acid can decrease the surface area and volume of micropores and increases the amount of acidic oxygen functional groups. While alkali modification increases the micropore volume of activated carbon and the amount of alkaline functional groups (Liu et al., 2005; Guo et al., 2007). It is reported that the increase of micropore volume and alkaline functional groups is beneficial to the adsorption of $\mathrm{H}_{2} \mathrm{~S}$ on $\mathrm{AC}$ (Guo et al., 2007; Zeng et al., 2007). And the adsorption of $\mathrm{H}_{2} \mathrm{~S}$ at low temperature is dominated by physisorption for micropore (Mochizuki et al., 2016). Meanwhile the chemical interaction between $\mathrm{NH}_{3}$ molecule and surface acidic functional groups plays a leading role in the adsorption of ammonia by activated carbon (Guo et al., 2005; Mochizuki et al., 2016). The adsorption behavior of $\mathrm{NH}_{3}$ and $\mathrm{H}_{2} \mathrm{~S}$ on $\mathrm{AC}$ prepared from petcoke with $\mathrm{KOH}$ chemical activation has been studied by Mochizuki et al. (Mochizuki et al., 2016). They found that the amount of acidic functionalities interfering with the $\mathrm{H}_{2} \mathrm{~S}$ adsorption on basic centers by giving electrostatic repulsion with $\mathrm{H}_{2} \mathrm{~S}$ molecules was much more than that of basic groups on activated carbon surface, which was the reason of the fact that adsorption of $\mathrm{H}_{2} \mathrm{~S}$ proceeded very slowly at the same adsorption condition than that of $\mathrm{NH}_{3}$.

Also it was reported that $\mathrm{AC}$ impregnated with $\mathrm{Zn}^{2+}$ and $\mathrm{Cu}^{2+}$ showed high pore volumes, surface areas, oxygencontaining groups, and the sorption capacities for the tested adsorbate in the study about AC using first-row transition metals ( $\mathrm{Co}, \mathrm{Ni}, \mathrm{Cu}$ and $\mathrm{Zn}$ ) as activating agents (Thue et al., 2017). Yi et al. have studied the simultaneous removal of $\mathrm{SO}_{2}, \mathrm{NO}$, and $\mathrm{CO}_{2}$ onto coconut shell activated carbon impregnated with metal nitrates $(\mathrm{Cu}, \mathrm{Ca}, \mathrm{Mg}, \mathrm{Zn})$ and found that $\mathrm{Cu}-\mathrm{SAC}$ showed the best adsorption ( $\mathrm{Yi}$ et al., 2014). Petit et al. revealed that the carbon impregnated with chloride of copper is an efficient ammonia adsorbent and the strong adsorption is based on formation of complexes with metal chlorides (Petit et al., 2007). Many researches confirmed wood-based activated carbon ground and mixed with $10 \%$ bentonite binders containing copper cations increased the capacity of carbon for hydrogen sulfide (Nguyen-Thanh and Bandosz, 2005). The results indicated that copper present in the small pores acts as a catalyst for oxygen activation, which oxidizes hydrogen sulfide to sulfur and sulfur dioxide. However, it takes too long to prepare the modified materials by this method and the pore structure of activated carbon is not well developed. Liang et al. revealed that the combinatory method of $\mathrm{HPHM}$ followed by $\mathrm{CuSO}_{4}$ impregnation modification, which increased the specific surface area, micropore area, micropore volume and average pore size of $A C$, obviously improved sulfur capacity of AC (Liang et al., 2014). It is reported that the treatment of $A C$ produced from kernel with water vapour at $250{ }^{\circ} \mathrm{C}$ results in increase of the specific surface area due to development of microporosity (Skubiszewska-Zięba et al., 2011).

Both $\mathrm{H}_{2} \mathrm{~S}$ and $\mathrm{NH}_{3}$ are present in waste gas from livestock farm waste gas, there is relatively little attention to simultaneous removal of $\mathrm{NH}_{3}$ and $\mathrm{H}_{2} \mathrm{~S}$ by $\mathrm{AC}$ adsorption. In this paper, the adsorption behavior of $A C$ modified by high-pressure hydrothermal modification (HPHM) and metal salt solution impregnation modification (MSIM), under the simulated environmental conditions of hydrogen sulfide and ammonia gas in the livestock farm, is studied. Meanwhile, the pore structure and surface functional groups of AC samples were characterized by BET, FTIR and Boehm titration method.

The mechanism of both $\mathrm{NH}_{3}$ and $\mathrm{H}_{2} \mathrm{~S}$ adsorption performance on MAC is explored further.

\section{Materials and methods}

\subsection{Sample preparation activity tests}

Activated carbon (diameter: $3 \mathrm{~mm}$ ) from the Xinhua Chemical Plant are selected as raw materials. The highpressure hydrothermal modification (HPHM) method is defined as the method that $A C$ samples are maintained in autoclave with distilled water according to the volume ratio (the volume of $A C$ in the natural accumulation state include the pore volume inside the activated carbon particles and the pore volume between the particles. All the activated carbon volume is defined in the same way in this paper) of $2: 3$ at a constant temperature for $3 \mathrm{~h}$, and then dried at $85^{\circ} \mathrm{C}$ for $3 \mathrm{~h}$. The metal salt solution impregnation modification (MSIM) is defined as the method that $A C$ samples impregnated with metal salt solution according to the volume ratio of $4: 3$ in a water bath at constant temperature for $2 \mathrm{~h}$. The prepared AC samples are thoroughly washed with distilled water until the $\mathrm{pH}$ value of filtrate became neutral, and then dried at $85^{\circ} \mathrm{C}$ for $3 \mathrm{~h}$. The preparation of modified activated carbon is shown in Table 1. 
Table 1. List of modified activated carbon

\begin{tabular}{|c|c|}
\hline Activated carbon type & Modification conditions \\
\hline RAC & Activated carbon (diameter: $3 \mathrm{~mm}$ ) from the Xinhua Chemical Plant \\
\hline GS270 & $\mathrm{AC}$ by $\mathrm{HPHM}$ under $270^{\circ} \mathrm{C}$ \\
\hline $\mathrm{MBC}$ & $\begin{array}{l}\text { AC by MSIM with different concentration of metal salt solution under the } \\
\text { condition of adsorption temperature. } \\
\mathrm{M}\left(\mathrm{Cu}\left(\mathrm{NO}_{3}\right)_{2}, \mathrm{Fe}\left(\mathrm{NO}_{3}\right)_{3}, \mathrm{Zn}\left(\mathrm{NO}_{3}\right)_{2}, \mathrm{ZnSO}_{4}, \mathrm{ZnCl}_{2}, \mathrm{CuSO}_{4} \text { or } \mathrm{CuCl}_{2}\right) \text { stands for metal } \\
\text { salt solution. } \mathrm{B}\left(30{ }^{\circ} \mathrm{C}, 60^{\circ} \mathrm{C} \text { or } 90{ }^{\circ} \mathrm{C}\right) \text { stands for adsorption temperature. } \mathrm{C} \\
(5 \%, 10 \% \text { or } 15 \%) \text { stands for concentration. }\end{array}$ \\
\hline MBCGS270 & AC by MSIM firstly then by HPHM. \\
\hline GS270MBC & AC by HPHM firstly then by MSIM. \\
\hline
\end{tabular}

\subsection{Activity tests}

The fixed bed reactor system used for $\mathrm{H}_{2} \mathrm{~S}$ and $\mathrm{NH}_{3}$ adsorption and the flow chart of adsorption removal of $\mathrm{H}_{2} \mathrm{~S}$ and $\mathrm{NH}_{3}$ are same as Ref (Liang et al., 2014). The $99.99 \% \mathrm{H}_{2} \mathrm{~S}$ and $\mathrm{NH}_{3}$ gas, diluted with $\mathrm{N}_{2}$ separately to simulate the livestock farm atmosphere, went through a fixed bed reactor of $20 \mathrm{ml} \mathrm{AC}$. The effects of modification conditions are investigated at $50{ }^{\circ} \mathrm{C}$, with gas space velocity of $900 \mathrm{~h}^{-1}$ and inlet concentration of $750-850 \mathrm{mg} \mathrm{m}^{-3}$. Meanwhile, the effect of operation conditions is investigated on $\mathrm{GS} 270 \mathrm{CuCl6010}$. The $\mathrm{H}_{2} \mathrm{~S}$ and $\mathrm{NH}_{3}$ concentration in gas phase is separately determined by means of lodometric method and Nessler's Reagents spectrophotometer (China, 2010; China, 2009).

\subsection{Activity tests}

The specific surface area, pore volume and pore structure of activated carbon samples were measured by Nitrogen isothermal adsorption method using Micromeritics ASAP2020 (Micrometrics, USA). The adsorption and desorption isotherms of $\mathrm{N}_{2}$ in the relative pressure of 0-0.99 were measured by static volumetric method at the liquid nitrogen temperature of $77 \mathrm{~K}$. The total specific surface area was calculated by BET model from the adsorption isotherms when the relative pressure $\mathrm{P} \cdot \mathrm{P}_{0}{ }^{-1}$ was less than 0.3 . The total pore volume was converted from the adsorption value of liquid nitrogen at relative pressure of 0.99. The micropore volume and specific surface area are calculated by the t-diagram method. The mesoporous volume is the total pore volume minus the micropore volume.

The content of acidic and basic surface groups is determined according to Boehm titration method improved by researchers. $1 \mathrm{~g}$ AC sample and $20 \mathrm{~mL}$ hydrochloric acid (sodium hydroxide) solution is placed in $250 \mathrm{~mL}$ iodine bottle (Lisovskii et al., 1997). After shaking, the bottle remains static for $48 \mathrm{~h} .10 \mathrm{~mL}$ of the filtrate is pipetted to the conical bottle and then titrated by standard sodium hydroxide (hydrochloric acid) solution.

The functional groups on the surface of the AC samples were studied using VERTEX70 Fourier transform infrared spectrometer (Bruker Co.) in the scanning range of $500-4000 \mathrm{~cm}^{-1}$ with a scanning speed of $0.2 \mathrm{~cm} \mathrm{~s}^{-1}$. The AC samples are of 200 mesh mixed with potassium bromide $(\mathrm{KBr})$ at the ratio of 300:1. The mixtures are ground into powder under infrared lamp and tableted for FTIR tested.

\section{Results and discussion}

\subsection{Effect of modification methods on $\mathrm{H}_{2} \mathrm{~S}$ and $\mathrm{NH}_{3}$ adsorption performance}

The adsorptions of $\mathrm{H}_{2} \mathrm{~S}$ and $\mathrm{NH}_{3}$ by $\mathrm{MAC}$ are shown in Figure $1 \mathrm{a}$ and b. The $\mathrm{NH}_{3}$ capacity of RAC, GS270, CuNO3010, GS270CuNO3010 and CuNO3010GS270 is 4.84, 5.98, 7.23, 16.41 and $9.13 \mathrm{mg} \cdot \mathrm{g}^{-1}$, respectively. The $\mathrm{H}_{2} \mathrm{~S}$ capacity of RAC, GS270, CuNO3010, GS270CuNO3010 and CuNO3010GS270 is $5.48,6.84,8.51,18.32$ and $10.11 \mathrm{mgg}^{-1}$ separately. The results demonstrate that the combinatory method of HPHM and MSIM is the combining of the advantages of both approaches, and the adsorption performance of MAC improved. The effect of HPHM followed by MSIM is much better than that of MSIM followed by HPHM, and the removal rate of the former is relatively high. The impregnant is more easily loaded in the developed $A C$ pores by HPHM. MSIM followed by HPHM cannot increase the loading amount further and may cause desorption of the originally loaded impregnant. Thus, modifying $A C$ by MSIM on the basis of HPHM could improve the $\mathrm{H}_{2} \mathrm{~S}$ and $\mathrm{NH}_{3}$ adsorption performance. a

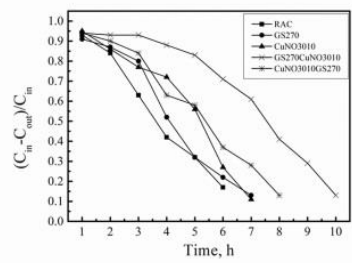

b

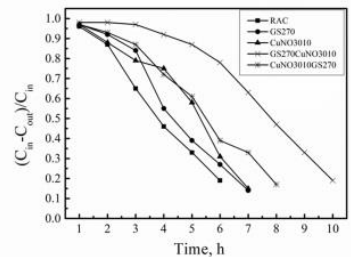

Figure 1. $\mathrm{NH}_{3}$ and $\mathrm{H}_{2} \mathrm{~S}$ adsorption curves of modification methods

The $\mathrm{H}_{2} \mathrm{~S}$ and $\mathrm{NH}_{3}$ adsorption performance on MAC by combinatory method with different metal salt solution is shown in Figure 2. Figure $2 a$ shows that the total adsorption capacity of GS270ZnNO3010 and GS270CuNO3010 is respectively more than 70\% higher than that of GS270FeNO3010. Copper salt and zinc salt solution are ideal impregnating solution. Figure $2 \mathrm{~b}$ shows that the total adsorption capacity of GS270CuCl3010 and GS270CuSO3010 is better than that of GS270ZnCl3010 and GS270ZnSO3010 and the total adsorption capacity of GS270CuCl3010, which reaches the best adsorption performance, is 2.8 times that of GS270. It is concluded that the adsorption effect of MAC by copper salt solution is 
better under the condition of the same anion in metal salt solution, due to the fact that copper is easier to chemically adsorb with $\mathrm{H}_{2} \mathrm{~S}$ and $\mathrm{NH}_{3}$; the adsorption efficiency of the anions in the impregnation solution is the best under the condition of the same cation in the metal salt solution, which may be because the smallest ion radius of the $\mathrm{Cl}^{-}$is easier to load on the activated carbon micropores. So, AC modified by $\mathrm{HPHM}$ at $270{ }^{\circ} \mathrm{C}$ followed by MSIM with $\mathrm{CuCl}_{2}$ solution has good $\mathrm{H}_{2} \mathrm{~S}$ and $\mathrm{NH}_{3}$ adsorption performance. a

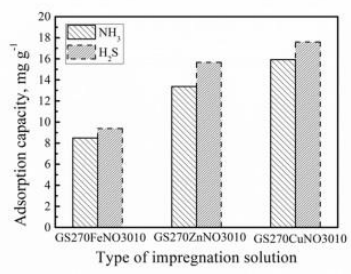

b

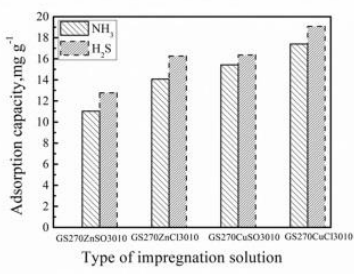

Figure 2. Adsorption capacity of different metallic salt solutions and different copper and zinc salt solutions $\mathrm{a}$

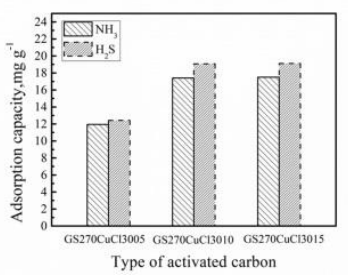

b

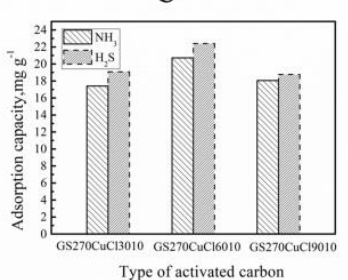

Figure 3. Adsorption capacity of different impregnation solution concentrations and different impregnation temperature

Figure 3 shows the effect of impregnation solution concentration and impregnation temperature on the $\mathrm{H}_{2} \mathrm{~S}$ and $\mathrm{NH}_{3}$ adsorption properties of MAC by the combined method. The $\mathrm{H}_{2} \mathrm{~S}$ and $\mathrm{NH}_{3}$ adsorption properties of MAC are obviously increased with the increase of impregnation solution concentration. It is found that the total adsorption capacity reached $36.4 \mathrm{mg} \mathrm{g}^{-1}, 3.5$ times as much as that of raw activated carbon, when the concentration of impregnation solution was increased to $10 \%$; the total adsorption capacity of MAC almost does not increase, due to the saturated adsorption of modified activated carbon on impregnating solution, when the concentration of impregnation solution continued to increase to $15 \%$. In addition, the distribution and uniformity of ions on $A C$ affect the catalytic activity of ions (Klinik and Grzybek, 1992 Liu et al., 2000). Figure $3 \mathrm{~b}$ shows that the total adsorption capacities of GS270CuCl3010, GS270CuCl6010 and GS270CuCl9010 are 3.6 times, 4.4 times and 3.7 times as much as those of RAC respectively and those of GS270CuCl6010 reaches the maximum. With the increase of impregnation temperature, the activity of solute ions increases and the diffusion rate is accelerated due to the accelerated speed of irregular movement, which makes it easier to load on the activated carbon. But too high activity of solute ions by further heating may cause adversely effect of solute ion loading on MAC. GS270 modified by HPHM by
MSIM with $10 \% \mathrm{CuCl}_{2}$ solution at $60^{\circ} \mathrm{C}$ achieves the optimal adsorption performance.

\subsection{Effect of different operation conditions on $\mathrm{H}_{2} \mathrm{~S}$ and $\mathrm{NH}_{3}$ adsorption performance}

Figure 4 shows the $\mathrm{H}_{2} \mathrm{~S}$ and $\mathrm{NH}_{3}$ adsorption performance on MAC (GS270CuCl6010) at adsorption temperature of $30^{\circ} \mathrm{C}$, $50{ }^{\circ} \mathrm{C}, 70{ }^{\circ} \mathrm{C}$ and $90{ }^{\circ} \mathrm{C}$, respectively. The $\mathrm{NH}_{3}$ adsorption capacity of MAC reaches its maximum at $50{ }^{\circ} \mathrm{C}$ and then decreases sharply, which indicates that Physical adsorption plays a major role in $\mathrm{NH}_{3}$ adsorption; the $\mathrm{H}_{2} \mathrm{~S}$ adsorption capacity of MAC reaches its maximum at $70{ }^{\circ} \mathrm{C}$ and decreases obviously at $90{ }^{\circ} \mathrm{C}$. This is because that the degree of enhancement of $\mathrm{H}_{2} \mathrm{~S}$ chemical adsorption on MAC is greater than that of weakening of physical adsorption at $70{ }^{\circ} \mathrm{C}$. It is concluded that temperature is a very important factor in the $\mathrm{NH}_{3}$ and $\mathrm{H}_{2} \mathrm{~S}$ adsorption on MAC which contains both physical adsorption and chemical adsorption. The optimum operating temperature for adsorption of $\mathrm{NH}_{3}$ and $\mathrm{H}_{2} \mathrm{~S}$ on $\mathrm{MAC}$ is considered at $50^{\circ} \mathrm{C}$.

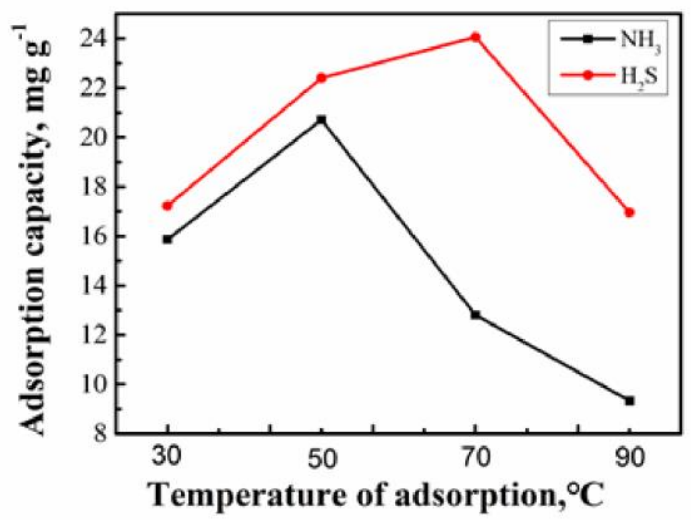

Figure 4. Adsorption capacity of GS270CuCl6010 at different adsorption temperature

Figures 5 show the adsorption properties of $\mathrm{NH}_{3}$ and $\mathrm{H}_{2} \mathrm{~S}$ on MAC at different gas space velocity. The $\mathrm{NH}_{3}$ capacity of $300,600,900$ and $1,200 \mathrm{~h}^{-1}$ is $14.15,18.41,20.47$ and 11.66 $\mathrm{mg} \mathrm{g}^{-1}$ separately. The $\mathrm{H}_{2} \mathrm{~S}$ capacity of $300,600,900$ and $1,200 \mathrm{~h}^{-1}$ is $14.61,18.85,22.23$ and $12.17 \mathrm{mg} \mathrm{g}^{-1}$ separately. The total adsorption capacity reaches the maximum at 900 $\mathrm{h}^{-1}$. Obviously, the retention time of high removal rate and breakthrough time at $300 \mathrm{~h}^{-1}$ are much longer than that at $1200 \mathrm{~h}^{-1}$. But the $\mathrm{NH}_{3}$ and $\mathrm{H}_{2} \mathrm{~S}$ adsorption capacity of $\mathrm{AC}$ would not increase with the decrease of gas space velocity, due to less $\mathrm{NH}_{3}$ and $\mathrm{H}_{2} \mathrm{~S}$ entering the fixed bed in unit time and the serious effect of external diffusion. Meanwhile high gas space velocity makes retention time not enough for $\mathrm{H}_{2} \mathrm{~S}$ and $\mathrm{NH}_{3}$ to be adsorbed before it overflows. So, $\mathrm{MAC}$ has good $\mathrm{H}_{2} \mathrm{~S}$ and $\mathrm{NH}_{3}$ adsorption performance under the condition of gas space velocity of $900 \mathrm{~h}^{-1}$. 


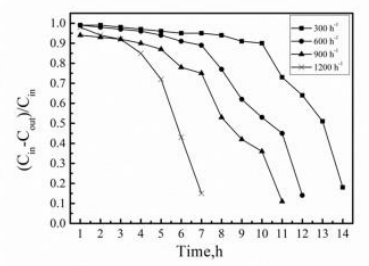

b

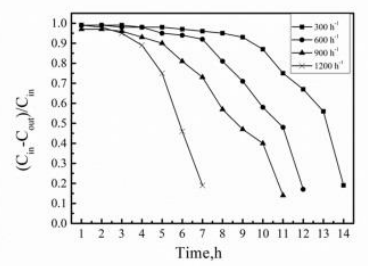

Figure 5. $\mathrm{NH}_{3}$ and $\mathrm{H}_{2} \mathrm{~S}$ adsorption curves of different space velocity

Figures 6 show the effect of $\mathrm{NH}_{3}$ and $\mathrm{H}_{2} \mathrm{~S}$ adsorption properties on MAC at different inlet concentrations of $\mathrm{NH}_{3}$ and $\mathrm{H}_{2} \mathrm{~S}$. The $\mathrm{NH}_{3}$ capacity of 150-250, 350-450, 550-650 and $750-850 \mathrm{mg} \mathrm{m}^{-3}$ is $13.87,19.35,24.17$ and $20.71 \mathrm{mg} \mathrm{g}^{-}$ ${ }^{1}$ separately. The $\mathrm{H}_{2} \mathrm{~S}$ capacity of 150-250, 350-450, 550650 and $750-850 \mathrm{mg} \mathrm{m}^{-3}$ is $14.85,21.34,26.20$ and 22.40 $\mathrm{mg} \mathrm{g}^{-1}$ separately. With the increase of the total inlet concentration, the breakthrough time of GS270CuCl6010 to $\mathrm{NH}_{3}$ and $\mathrm{H}_{2} \mathrm{~S}$ and the retention time of high removal rate are both shortened, but the $\mathrm{NH}_{3}$ and $\mathrm{H}_{2} \mathrm{~S}$ capacity generally increases except at $750-850 \mathrm{mg} \mathrm{m}^{-3}$.The condition of total inlet concentration of $550-650 \mathrm{mg} \mathrm{m}^{-3}$ is beneficial to $\mathrm{NH}_{3}$ and $\mathrm{H}_{2} \mathrm{~S}$ adsorption properties on MAC.

\subsection{Characterization and analysis for $M A C$}

The BET characterization for AC samples is summarized in Table 2. The surface area, average pore size, total pore volume, mesopore volume, micropore volume and micropore area increase by $151.1335 \mathrm{~m}^{2} \mathrm{~g}^{-1}(77 \%), 0.7999$ $\mathrm{nm}(30 \%), 0.105169 \mathrm{~cm}^{3} \mathrm{~g}^{-1}(80 \%), 0.031197 \mathrm{~cm}^{3} \mathrm{~g}^{-1}(58 \%)$, $0.073972 \mathrm{~cm}^{3} \mathrm{~g}^{-1}(95 \%)$ and $83.5401 \mathrm{~m}^{2} \mathrm{~g}^{-1}(49 \%)$ separately after modification by $\mathrm{HPHM}$ at $270{ }^{\circ} \mathrm{C}$. Among them, total pore volume, surface area and micropore volume increased significantly, which is the result of the opening of the originally closed or incomplete activated carbon pores by internal and external pressure difference. Increase in the quantity of mesopores and micropores make the surface area increase. Similar results to the present study have been reported by other researchers (SkubiszewskaZięba et al., 2011). In addition, the pore structure of GS270

is more developed than that of CuCl6010GS270 which is more developed than that of GS270CuCl6010. It indicates that HPHM followed by MSIM can increase the amount of modifiers loaded in the pore. The surface area, average pore size, total pore volume, mesopore volume, micropore volume and micropore area of adsorbed GS270CuCl6010 reduce by $19 \%, 18 \%, 28 \%, 7 \%, 38 \%$ and $22 \%$ compared with GS270CuCl6010. The obvious decrease of micropore volume indicates that the adsorption of $\mathrm{NH}_{3}$ and $\mathrm{H}_{2} \mathrm{~S}$ by MAC is mainly carried out in micropores, which play a important role in the adsorption process. Meanwhile, the slightly decrease of mesopore volume indicates that mesopore acts as the channel in the adsorption process. a

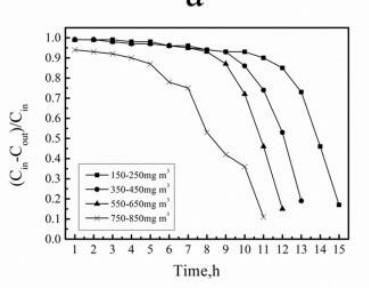

$\mathrm{b}$

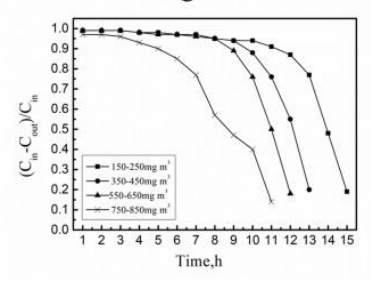

Figure 6. $\mathrm{NH}_{3}$ and $\mathrm{H}_{2} \mathrm{~S}$ adsorption curves of different total inlet concentration

The content of surface acidic and alkaline groups on activated carbon on AC samples by Boehm titration is collected in Table 3. It can be seen the content of acid and base functional groups on the surface of MAC by HPHM both increase by more than $40 \%$ than that of RAC due to the greatly increase of specific surface area. It is one of the reasons that the adsorption property of GS270 is better than that of RAC. While the content of surface acidic and alkaline groups of GS270, CuCl6010, CuCl6010GS270, GS270CuCl6010, GS270ZnCl6010 and GS270FeCl6010 is almost unchanged. In this experiment, the difference of adsorption properties of various AC samples is not determined by the content of surface acidic and alkaline groups.

Table 2. Pore structure measure of modified activated carbon

\begin{tabular}{|c|c|c|c|c|c|c|}
\hline Type of AC & $\begin{array}{c}\text { Surface area } \\
\left(\mathrm{m}^{2} \mathrm{~g}^{-1}\right)\end{array}$ & $\begin{array}{l}\text { Average pore size } \\
(\mathrm{nm})\end{array}$ & $\begin{array}{c}\text { Total pore } \\
\text { volume }\left(\mathrm{cm}^{3} \mathrm{~g}^{-1}\right)\end{array}$ & $\begin{array}{c}\text { Mesopore } \\
\text { volume }\left(\mathrm{cm}^{3} \mathbf{g}^{-1}\right)\end{array}$ & $\begin{array}{c}\text { Micropore } \\
\text { volume }\left(\mathrm{cm}^{3} \mathrm{~g}^{-1}\right)\end{array}$ & $\begin{array}{l}\text { Micropore } \\
\text { area }\left(\mathrm{m}^{2} \mathrm{~g}^{-1}\right)\end{array}$ \\
\hline RAC & 196.3352 & 2.6787 & 0.131482 & 0.053322 & 0.078160 & 169.3630 \\
\hline GS270 & 347.4687 & 3.4786 & 0.236651 & 0.084519 & 0.152132 & 252.9031 \\
\hline CuCl6010GS270 & 347.3212 & 3.4692 & 0.234332 & 0.083307 & 0.151025 & 252.6828 \\
\hline GS270CuCl6010 & 346.1785 & 3.3455 & 0.221049 & 0.072755 & 0.148294 & 251.9526 \\
\hline $\begin{array}{l}\text { GS270CuCl6010 } \\
\text { (adsorbed) }\end{array}$ & 278.9070 & 2.7401 & 0.159708 & 0.067702 & 0.092006 & 197.1655 \\
\hline
\end{tabular}

FTIR absorption spectra of AC samples are recorded as shown in Figure 7. The main absorption peaks at 1089, 1417, 1627, 2877, 2925 and $3444 \mathrm{~cm}^{-1}$ in the spectrum of AC samples are assigned to the stretching vibration characteristic peak of ether group $(-\mathrm{C}-\mathrm{O})$, carboxylate group (symmetric and asymmetric), carbonyl group $(-\mathrm{C}=\mathrm{O})$, aliphatic group $\left(-\mathrm{CH}_{3}\right)$, aliphatic group $\left(-\mathrm{CH}_{2}\right)$ and hydroxyl group (intermolecular association). Figure 7a shows that the characteristic peak intensity of RAC at 1089 $\mathrm{cm}^{-1}$ is obviously higher than that of MAC by combined method modification and single HPHM but is basically consistent with that of MAC by single MSIM; the characteristic peak intensity of $A C$ at $1417 \mathrm{~cm}^{-1}$ almost disappeared by single HPHM, but increased slightly by 
combined method modification and single MSIM; At 2877 $\mathrm{cm}^{-1}$, the characteristic peaks of all MAC samples belonging to aliphatic group disappeared basically; the quantity of carbonyl group, and hydroxyl group increases significantly by the combined method modification. So, carbonyl group and hydroxyl group are conducive to the removal of $\mathrm{H}_{2} \mathrm{~S}$ and $\mathrm{NH}_{3}$. Ether group is not favorable for adsorption. That is one of the reasons why combinatory method is better than single HPHM or MSIM. Figure 7b shows that the quantity of carbonyl group and hydroxyl group of MAC impregnated with $\mathrm{CuCl}_{2}$ and $\mathrm{ZnCl}_{2}$ solution is larger than that of $\mathrm{FeCl}_{3}$ solution. And the transformation and decomposition to ether group of impregnation modification by $\mathrm{CuCl}_{2}$ and $\mathrm{ZnCl}_{2}$ solution are stronger than that of $\mathrm{FeCl}_{3}$. That is one of the reasons why MAC impregnated $\mathrm{CuCl}_{2}$ or $\mathrm{ZnCl}_{2}$ solution is better than that of $\mathrm{FeCl}_{3}$. Figure 7c shows that the characteristic peak at 1627 $\mathrm{cm}^{-1}$ of MAC impregnated with $5 \% \mathrm{CuCl}_{2}$ solution is slightly weaker than those of $10 \%$ and $15 \% \mathrm{CuCl}_{2}$ solutions. $10 \%$ $\mathrm{CuCl}_{2}$ solution is high enough for the modification of activated carbon sample. The following conclusions can be drawn: Modification of surface functional groups on AC by combined method achieves the best effect.

Table 3. Content of surface acidic and alkaline groups on activated carbon

\begin{tabular}{ccc}
\hline Type of AC & Content of acidic group (mmol $\mathbf{~ g}^{-\mathbf{}}$ ) & Content of acidic group (mmol $\mathbf{~}^{\mathbf{1}}$ ) \\
\hline RAC & 0.8065 & 0.7712 \\
\hline GS270 & 1.2946 & 1.2017 \\
\hline CuCl6010 & 1.3078 & 1.2282 \\
\hline CuCl6010GS270 & 1.2894 & 1.2603 \\
\hline GS270CuCl6010 & 1.3669 & 1.2895 \\
\hline GS270FeCl6010 & 1.3078 & 1.2439 \\
\hline GS270ZnCl6010 & 1.3326 & 1.2504 \\
\hline
\end{tabular}

a

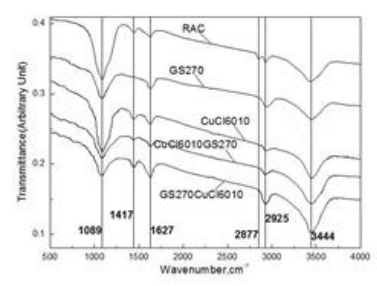

b

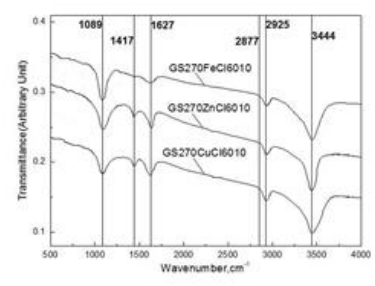

$\mathrm{c}$

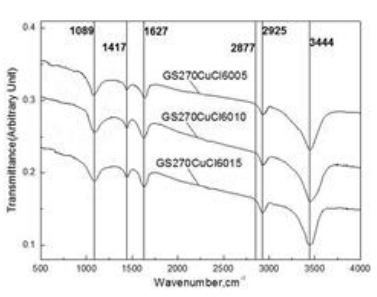

Figure 7. (a) FTIR spectra of activated carbon modified by different methods. (b) FTIR spectra of activated carbon modified by different impregnation solution. (c) FTIR spectra of activated carbon modified by different impregnation solution concentrations

\subsection{Mechanism discussion}

The content of acid and base functional groups on the surface of MAC by HPHM both increase by more than $40 \%$ than that of RAC due to the greatly increase of specific surface area. But the content of surface acidic and alkaline groups of AC samples by different modification methods is almost unchanged which indicates that the content of surface acidic and alkaline groups is not a deciding factor of the difference of adsorption properties on various AC samples. The surface area, average pore size, total pore volume, mesopore volume, micropore volume and micropore area of AC by HPHM at $270{ }^{\circ} \mathrm{C}$ increase by $77 \%$, $30 \%, 80 \%, 58 \%, 95 \%$ and $49 \%$ separately, which is the result of the opening of the originally closed or incomplete activated carbon pores by internal and external pressure difference. The adsorption capacity of GS270 and GS270CuCl6010 is separately 1.24 times and 4.4 times as high as that of RAC. While the micropore volume and mesopore volume of CuCl6010GS270 are slightly lower than that of GS270. It means that modifier doesn't take up too much of the pore volume of the activated carbon. Similar results to the present study have been reported (Nguyen-Thanh and Bandosz, 2005; Liang et al.; 2014; Zhang et al., 2016). And Copper is loaded in the inner space oft AC. In addition, the obvious decrease of micropore volume of adsorbed GS270CuCl6010, comparing with GS270CuCl6010, indicates that the adsorption of $\mathrm{NH}_{3}$ and $\mathrm{H}_{2} \mathrm{~S}$ by $\mathrm{MAC}$ is mainly carried out in micropore, which is important in the adsorption process. Meanwhile, the slightly decrease of mesopore volume indicates that mesopore acts as the channel in the adsorption process. Mochizuki also thought micropores play an important role in the adsorption process of $\mathrm{H}_{2} \mathrm{~S}$ (Mochizuki et al., 2016; Wang et al., 2019). It was reported that copper on the surface of activated carbon may be present mostly in the form of $\mathrm{CuCl}_{2}$ (Kim and Yie, 2005). Copper in carbon micropores acts as an oxygen activator until the complete reduction to $\mathrm{Cu}^{1+}$ from $\mathrm{Cu}^{2+}$ occurs and then $\mathrm{Cu}_{2} \mathrm{~S}$ is deposited on the surface (Nguyen-Thanh and Bandosz, 2005). Reaction of copper with $\mathrm{NH}_{3}$ to form $\mathrm{Cu}\left(\mathrm{NH}_{3}\right)_{2} \mathrm{Cl}_{2}$, involving series of associative and dissociative processes (Petit et al., 2007). These lead to the more active adsorption of both $\mathrm{H}_{2} \mathrm{~S}$ and $\mathrm{NH}_{3}$ on MAC by HPHM followed by MSIM. Furthermore, one of the main reasons why combinatory method is better than single method is the increase of useful groups and the reduction of harmful 
groups in quantity. Carbonyl group $(-\mathrm{C}=\mathrm{O})$ and hydroxyl group (intermolecular association) are conducive to the removal of $\mathrm{H}_{2} \mathrm{~S}$ and $\mathrm{NH}_{3}$ and ether group $(-\mathrm{C}-\mathrm{O})$ is not favorable for adsorption. The reduction of ether group can promote the reduction of $\mathrm{Cu}^{2+}$ by weakening the interaction force between $\mathrm{Cu}^{2+}$ and carrier (Zhang et al., 2016). And Hydrogen atoms of $\mathrm{NH}_{3}$ and $\mathrm{H}_{2} \mathrm{~S}$ can interact with oxygen in the form of carbonyl groups $(-\mathrm{C}=\mathrm{O})$ and hydroxyl groups (intermolecular association) on MAC (Miyauchi and Ohba, 2019; Arellano-García et al., 2015; Guo et al., 2007; Lee and Reucroft, 1999). At low temperature, the adsorption of $\mathrm{NH}_{3}$ and $\mathrm{H}_{2} \mathrm{~S}$ by activated carbon is mainly physical adsorption, and the chemisorption can be enhanced by increasing adsorption temperature, which makes $\mathrm{NH}_{3}$ and $\mathrm{H}_{2} \mathrm{~S}$ more easily adsorbed by modified activated carbon to some extent. But the adsorption of modified activated carbon is the result of the interaction of physical adsorption and chemical adsorption. At $50{ }^{\circ} \mathrm{C}$, the combined action of physical and chemical adsorption reaches the maximum.

The research team is currently conducting further research on the removal of ammonia and hydrogen sulfide from livestock farms. The copper modified catalyst life, easy regeneration method of catalyst, amplification experiments on catalytic reactor, energy issues of technology application - Solar Energy Utilization, and noise reduction methods were studied and investigated.

\section{Conclusions}

From the experimental studies of $\mathrm{H}_{2} \mathrm{~S}$ and $\mathrm{NH}_{3}$ adsorption onto MAC, the following conclusions can be drawn:

(1) The optimal adsorption performance can be achieved by the combinatory method of high-pressure hydrothermal modification (HPHM) at $270{ }^{\circ} \mathrm{C}$ followed by the metal salt solution impregnation modification (MSIM) with $10 \% \mathrm{CuCl}_{2}$ solution at $60^{\circ} \mathrm{C}$ for $2 \mathrm{~h}$ under the simulated environmental conditions of hydrogen sulfide and ammonia gas in the livestock farm.

(2) The adsorption capacity of GS270 is 1.3 times that of the raw activated carbon. The adsorption capacity of GS270CuCl2 solution at $60{ }^{\circ} \mathrm{C}$ was 4.4 times that of the activated carbon. Modifying AC by the combinatory method of HPHM and MSIM could improve the $\mathrm{H}_{2} \mathrm{~S}$ and $\mathrm{NH}_{3}$ adsorption performance.

(3) Adsorption of $\mathrm{NH}_{3}$ and $\mathrm{H}_{2} \mathrm{~S}$ by AC is mainly carried out in micropore and mesopore which act as the adsorption channel. After impregnation modification with $\mathrm{CuCl}_{2}$ solution of $\mathrm{AC}$ by HPHM, $\mathrm{Cu}^{2+}$ loaded in the micropores react with $\mathrm{NH}_{3}$ and $\mathrm{H}_{2} \mathrm{~S}$ to achieve the adsorption of both $\mathrm{NH}_{3}$ and $\mathrm{H}_{2} \mathrm{~S}$. $\mathrm{NH}_{3}$ and $\mathrm{H}_{2} \mathrm{~S}$ can therefore adsorb onto active adsorption sites (Carbonyl group and hydroxyl group) provided by oxygen functional groups via hydrogen boding. Ether group $(-\mathrm{C}-\mathrm{O})$ is not favorable for adsorption. Both $\mathrm{NH}_{3}$ and $\mathrm{H}_{2} \mathrm{~S}$ adsorption of MAC is the result of the interaction of physical adsorption and chemical adsorption. AC modified by the combinatory method of high-pressure hydrothermal modification and the metal salt solution impregnation modification can significantly improve the adsorption performance. After regeneration treatment, its adsorption performance to a large extent to recover. MAC, as a highly efficient and economical industrial adsorbent, is conducive to the radical treatment of waste gas pollution from livestock farm.

\section{Acknowledgements}

The authors gratefully acknowledge the financial support of National Natural Science Foundation of China (21776192).

\section{References}

Arellano-García L., Dorado A.D., Morales-Guadarrama A., et al. (2015), Modeling the effects of biomass accumulation on the performance of a biotrickling filter packed with PUF support for the alkaline biotreatment of dimethyl disulfide vapors in air, Applied Microbiology and Biotechnology, 99, 97-107.

Chen Y. and Wang S.J. (2014), Environmental pressure of intensive livestock breeding in China and the revelation of environmental governance from developed countries, Resour Environ Yangtze Basin, 23, 862-868.

Datta I. and Allen D.G. (2005), Biofilter technology, In Biotechnology for Odor and Air Pollution Control, 125-145.

Environmental Protection Department of the People's Republic of China. Water quality - Determination of ammonia - Nessler's reagent spectrophotometry: HJ535-2009. Beijing: China Environmental Science Press, 2009.

Gao Y.C., Kuang Z.S., Pan M.S., et al. (2004), Biological controlling of odor and its pollutants in pig farm, Ecological Science, 23, 227-230+235.

Guo J., Luo Y., Lua A.C., et al. (2007), Adsorption of hydrogen sulphide $\left(\mathrm{H}_{2} \mathrm{~S}\right)$ by activated carbons derived from oil-palm shell, Carbon, 45, 330-336.

Guo J., Xu W.S., Chen Y.L., et al. (2005), Adsorption of $\mathrm{NH}_{3}$ onto activated carbon prepared from palm shells impregnated with $\mathrm{H}_{2} \mathrm{SO}_{4}$, Journal of Colloid and Interface Science, 281, 285-290.

Harihastuti N., Purwanto P. and Istadi I. (2015), 2nd International Conference of Chemical and Material Engineering, Semarang, Indonesia, 2015.

Heber A.J., Ni J.Q., Lim T.T., et al. (2006), Quality assured measurements of animal building emissions: Gas concentrations, Journal of the Air \& Waste Management Association, 56, 1472-1483.

Kim D.J. and Yie J.E. (2005), Role of copper chloride on the surface of activated carbon in adsorption of methyl mercaptan, Journal of Colloid and Interface Science, 283, 311-315.

Kim K.Y., Ko H.J., Kim H.T., et al. (2008), Quantification of ammonia and hydrogen sulfide emitted from pig buildings in Korea, Journal of Environmental Management, 88, 195-202.

Klinik J. and Grzybek T. (1992), The influence of the addition of cobalt nickel, manganese and vanadium to active carbons on their efficiency in $\mathrm{SO}_{2}$ removal from stack gases, Fuel, 71, 1303-1308.

Lee W.H. and Reucroft P.J. (1999), Vapor adsorption on coal-and wood-based chemically activated carbons: (III) $\mathrm{NH}_{3}$ and $\mathrm{H}_{2} \mathrm{~S}$ adsorption in the low relative pressure range, Carbon, 37, 2126.

Li F., Cheng S., Yu H., et al. (2016), Waste from livestock and poultry breeding and its potential assessment of biogas energy in rural China, Journal of Cleaner Production, 126, 451460.

Liang M., Zhang C. and Zheng $\mathrm{H}$. (2014), The removal of $\mathrm{H}_{2} \mathrm{~S}$ derived from livestock farm on activated carbon modified by 
combinatory method of high-pressure hydrothermal method and impregnation method, Adsorption, 20, 525-531.

Liang M.S., Chen W.J. and Zheng H.T. (2014), Removal of $\mathrm{H}_{2} \mathrm{~S}$ derived from livestock farm on activated carbon modified by copper sulfate, Journal of Civil, Architectural \& Environmental Engineering, 36, 131-136.

Liao R.J. and Chen Y.C. (2017), Characteristics of ammonia emission from large-scale livestock/poultry breeding and its mitigation counter measures in Chongqing, Chinese Journal of Eco-Agriculture, 25, 769-777.

Lisovskii A., Shter G.E., Semiat R., et al. (1997), Adsorption of sulfur dioxide by active carbon treated by nitric acid: II. Effect of preheating on the adsorption properties, Carbon, 35, 1645-1648.

Liu B., Wang W.L., Liu X., et al. (2017), A review of researches on composition, measurement and assessment of odorants in livestock and poultry, Journal of Ecology and Rural Environment, 33, 872-881.

Liu H.B., Yang B. and Xue N.D. (2005), Effects of acidic and basic modification on activated carbon for adsorption of toluene, Environmental Science, 37, 3670-3678.

Liu S.J., Liu Z.Y., Zhu Z.P., et al. (2000), Preparation and selection of highly active carbon-supported desulfurizers, Coal Conversion, 23, 53-58.

Matulaitis R. (2015), The effect of floating covers on gas emissions from liquid pig manure, Chilean Journal of Agricultural Research, 75, 232-238.

Miyauchi M. and Ohba T. (2019), Enhancement of NH3 and water adsorption by introducing electron-withdrawing groups with maintenance of pore structures, Adsorption-Journal of the International Adsorption Society, 25, 87-94.

Mochizuki T., Kubota M., Matsuda H., et al. (2016), Adsorption behaviors of ammonia and hydrogen sulfide on activated carbon prepared from petroleum coke by $\mathrm{KOH}$ chemical activation, Fuel Processing Technology, 144, 164-169.

Mudliar S., Giri B., Padoley K., et al. (2010), Bioreactors for treatment of vocs and odours - a review, Journal of Environmental Management, 91, 1039-1054.

Nguyen-Thanh D. and Bandosz T.J. (2005), Activated carbons with metal containing bentonite binders as adsorbents of hydrogen sulfide, Carbon, 43, 359-367.

Nicell J.A. (2009), Assessment and regulation of odour impacts, Atmospheric Environment, 43, 196-206.

Osorio J.A., Ferreira Tinoco I.L.D.A. and Ciro H.J. (2009), Ammonia: a review of concentration and emission models in livestock structures, Dyna, 76, 89-99.

People's Republic of China State Administration of Quality Supervision Inspection and quarantine (2010), Natural GasDetermination of Sulfur Compound-Part 1: Determination of Hydrogen Sulfide Content By lodometric Titration Method: GB/T11060.1-2010, Beijing: China Standard Press.

Petit C., Karwacki C., Peterson G., et al. (2007), Interactions of ammonia with the surface of microporous carbon impregnated with transition metal chlorides, The Journal of Physical Chemistry C, 111, 12705-12714.

Rene E.R., Veiga M.C. and Kennes C. (2012), Combined biological and physicochemical waste-gas cleaning techniques, Journal of Environmental Science and Health, Part A, 47, 920-939.

Schiffman S.S. and Williams C.M. (2005), Science of odor as a potential health issue, Journal of Environmental Quality, 34, 129-138.
Skubiszewska-Zięba J., Sydorchuk V.V., Gun'ko V.M., et al. (2011), Hydrothermal modification of carbon adsorbents, Adsorption, 17, 919-927.

Thue P.S., Lima E.C., Sieliechi J.M., et al. (2017), Effects of first-row transition metals and impregnation ratios on the physicochemical properties of microwave-assisted activated carbons from wood biomass, Journal of Colloid and Interface Science, 486, 163-175.

Wang Q.N., Huang B.F., Bi H.W., et al. (2019), Desulfurizing property of copper modified activated carbon, Environmental Science Survey, 38, 66-70.

Xu X.F. (2007), Design of odor control system for the third stage project in Binhe wastewater treatment plant, China Water and Wastewater, 23, 52-54.

Yi H., Zuo Y., Liu H., et al. (2014), Simultaneous removal of $\mathrm{SO}_{2}$, $\mathrm{NO}$, and $\mathrm{CO}_{2}$ on metal-modified coconut shell activated carbon, Water, Air, \& Soil Pollution, 225, 1965.

Zeng F., Liao X.F., Li Y., et al. (2007), Preparation of sludge-strawbased activated carbon and its adsorption of $\mathrm{H}_{2} \mathrm{~S}$, Acta Scientiae Circumstantiae, 37, 4269-4276.

Zhang G.Q., Zheng H.Y., Hao Z.Q., et al. (2016), Effect of activated carbon surface chemistry on the properties of Cu particles and the catalytic performance for oxidative carbonylation of methanol, Chemical Journal of Chinese Universities, 37, 13801389.

Zheng L.S., Chen Z.P., Lin P.Z., et al. (2014), Discussion on emission standards for odor pollutants, China Water and Wastewater, 30, $74-75+85$. 